\title{
A comparison of nephrotoxicity between patients with a solitary-functioning kidney and those with bilateral-functioning kidneys in cisplatin-based chemotherapy for advanced urothelial carcinoma: a Japanese retrospective multi-institutional study
}

Takamitsu Inoue ${ }^{1}$, Jun Miyazaki², Daishi Ichioka², Shintaro Narita' ${ }^{1}$, Susumu Kageyama ${ }^{3}$, Mikio Sugimoto ${ }^{4}$, Koji Mitsuzuka ${ }^{5}$, Yusuke Shiraishi ${ }^{6}$, Hidefumi Kinoshita ${ }^{7}$, Hironobu Wakeda ${ }^{8}$, Takeshi Nomoto ${ }^{9}$, Eiji Kikuchi ${ }^{10}$, Yoshiyuki Matsui ${ }^{11}$, Keiko Fujie ${ }^{12,13}$, Tomonori Habuchi ${ }^{1}$ and Hiroyuki Nishiyama ${ }^{2^{*}}$ (D)

\footnotetext{
Abstract

Background: To compare the prevalence of nephrotoxicity between patients with a solitary-functioning kidney versus those with bilateral-functioning kidneys during the administration of cisplatin-based chemotherapy for advanced urothelial carcinoma.

Methods: We retrospectively analyzed 244 advanced urothelial carcinoma patients treated with cisplatin-based chemotherapy between 2004 and 2010 at 17 institutes in Japan. The 24 h creatinine clearance, Cockcroft-Gault formula, and estimated glomerular filtration rate equation (eGFR), were compared before all chemotherapies. The urinary tract function status was determined based on the data of nephroureterectomy, hydronephrosis, and relief of upper urinary tract obstruction. A total of 244 patients were divided into four groups according to their urinary tract functioning status and eGFR results, including bilateral-functioning kidneys with pretreatment eGFR $\geq 60 \mathrm{~mL} / \mathrm{min} / 1.73 \mathrm{~m}^{2}$ group $(n=83,34$. $0 \%)$; a solitary-functioning kidney with pretreatment eGFR $\geq 60 \mathrm{~mL} / \mathrm{min} / 1.73 \mathrm{~m}^{2}$ group $(n=36,14.8 \%)$; bilateralfunctioning kidneys with pretreatment eGFR $<60 \mathrm{~mL} / \mathrm{min} / 1.73 \mathrm{~m}^{2}$ group $(n=45,18.4 \%)$; and a solitaryfunctioning kidney with pretreatment eGFR $<60 \mathrm{~mL} / \mathrm{min} / 1.73 \mathrm{~m}^{2}$ group $(n=80,32.8 \%)$.

\footnotetext{
* Correspondence: nishiuro@md.tsukuba.ac.jp

${ }^{2}$ Department of Urology, Faculty of Medicine, University of Tsukuba, 1-1-1,

Tennodai, Tsukuba, Ibaraki 305-8575, Japan

Full list of author information is available at the end of the article
} 
(Continued from previous page)

Results: The prevalence of nephrotoxicity with impaired eGFR of $>10 \%$ and 30\% from baseline in the post-third-course of chemotherapy was significantly higher in patients with bilateral-functioning kidneys than in those with a solitary-functioning kidney, among patients with pretreatment eGFR $<60 \mathrm{~mL} / \mathrm{min} / 1.73 \mathrm{~m}^{2}(p=0.023$ and $p=0.026$ ). During all courses of chemotherapy, the prevalence of nephrotoxicity with impaired eGFR of $>20 \%$ from baseline were significantly higher in patients with bilateral-functioning kidneys than those with a solitary-functioning kidney among patients with pretreatment eGFR $<60 \mathrm{~mL} / \mathrm{min} / 1.73 \mathrm{~m}^{2}(p=0.034$ ), whereas no significant difference was observed among patients with pretreatment eGFR $\geq 60 \mathrm{~mL} / \mathrm{min} / 1.73 \mathrm{~m}^{2}$.

Conclusions: The results suggest that cisplatin-based chemotherapy may have more nephrotoxicity in patients with bilateral-functioning kidneys than in those with a solitary-functioning kidney.

Keywords: Urothelial carcinoma, Cisplatin, Nephrotoxicity, Nephroureterectomy, Solitary kidney

\section{Background}

Cisplatin-based combination chemotherapies have been the standard regimen for patients with advanced urothelial carcinoma (UC) since the approval of cisplatin in the United States in 1993 [1]. The standard regimens for patients with advanced UC are methotrexate, vinblastine, doxorubicin, and cisplatin (MVAC), or gemcitabine and cisplatin (GC). The median overall survival of these two regimens is 13.8 and 14.8 months, respectively [2, 3]. Although cisplatin is a key drug for the treatment of patients with advanced UC, a significant nephrotoxicity associated with cisplatin therapy restricts its use to patients with appropriate kidney function [4].

To estimate the suitability of cisplatin treatment before the initiation of therapy, the Cockcroft-Gault formula (CG), a modification of diet in renal disease (MDRD) formula, and/or a $24 \mathrm{~h}$ creatinine clearance test (24hCCr) have been widely used to estimate a glomerular filtration rate (GFR) [5]. A patient with a GFR $<60 \mathrm{~mL} /$ min is usually defined as having the chronic renal disease (CKD) and cisplatin-ineligible [4]. For cisplatin-ineligible patients, carboplatin-based combination chemotherapies have been the most favored regimens, using Calvert's formula to adjust the dose of carboplatin according to the estimated GFR. Outcomes for cisplatin-eligible advanced UC patients treated with carboplatin-based chemotherapies, such as gemcitabine plus carboplatin, with a median overall survival of 9.0 months, were poorer than those for patients treated with cisplatin-based chemotherapies $[6,7]$. However, in cisplatin-ineligible advanced UC patients, the median overall survival of patients treated with carboplatin-based combination chemotherapies are reported 7.2-16.3 months [8-11], which is almost similar (i.e., around 10 months) in those treated with cisplatinbased chemotherapies, including the reduction of cisplatin $[12,13]$ or a split dose of cisplatin regimens [14-16].

Following radical nephroureterectomy, approximately $78-81 \%$ of patients with upper tract urothelial carcinoma (UTUC) are cisplatin-ineligible (with eGFR $<60 \mathrm{~mL} / \mathrm{min} /$ $\left.1.73 \mathrm{~m}^{2}\right)[17,18]$. Therefore, the recommended treatment for patients with advanced UTUC, listed in the clinical guidelines (e.g., the 2015 European Association of Urology Guidelines), is neoadjuvant chemotherapy only, with consideration made for the fact that chemotherapy-related nephrotoxicity from platinum derivatives may significantly reduce survival $[9,19]$. However, Lene et al. recently showed that renal cell carcinoma patients with surgicallyinduced CKD (CKD-S) have a relatively low risk of progressive renal function decline, whereas those with medically-induced CKD (CKD-M) have an increased risk [20]. In addition, a previous report from Korea showed that cisplatin-based chemotherapy was safe in the majority of patients who underwent nephroureterectomy [21]. It is plausible that the CKD-S patients, who underwent nephroureterectomy or who have ipsilateral hydronephrosis and an intact solitary-functioning kidney without medical comorbidities, have some potential endurance for nephrotoxicity in cisplatin-based chemotherapy. However, currently there is an insufficient amount of data to support recommendations of chemotherapy regimens for CKD-S advanced UC patients with a solitary-functioning kidney $[5,19]$.

In this study, the prevalence of nephrotoxicity in cisplatin-based chemotherapy for advanced UC was retrospectively compared in cisplatin-ineligible patients with a solitary-functioning kidney versus those with bilateral-functioning kidneys, using a Japanese multiinstitutional database.

\section{Methods}

In this study, we retrospectively evaluated 345 advanced or unresectable UC patients who underwent systemic chemotherapy between 2004 and 2010 at 17 institutes in Japan (CURE study group). Patients who underwent neo-adjuvant chemotherapy or chemoradiation for bladder preservation were excluded from this study. All cases required pathological confirmation of $\mathrm{UC}$, except for patients with upper urinary tract cancer, who were instead diagnosed based on positive urinary cytology and radiological examinations. The concept of the study was 
approved by the internal ethical committees at all of the 17 institutions involved. Informed consent for chemotherapies was obtained from all the patients. Informed consent to participate in the study was not obtained with an opt-out statement on the website of all of the 17 institutions involved. Follow-up data were acquired in December 2013. All data were collected from medical records at each institution and registered by a secretariat server on the website.

We selected 244 patients, who underwent cisplatin-based combination regimens as a first-line chemotherapy and had data on their kidney function status. The cisplatin-based combination chemotherapies included in this study were GC ( $n=103,42.2 \%)$; MVAC ( $n=98,40.2 \%)$; methotrexate, epirubicin, and cisplatin (MEC) $(n=35,14.3 \%)$; and gemcitabine, cisplatin, and docetaxel (GCD) $(n=8,3.3 \%)$. The selection of chemotherapy regimens was based on the preference of each institute.

The urinary tract function status was evaluated and defined by the following criteria: 1) a patient who underwent radical nephroureterectomy was defined as having a contralateral solitary-functioning kidney; 2) a patient who had hydronephrosis (regardless of grade) was defined as having an ipsilateral nonfunctional kidney; and 3) a patient who underwent a relief of upper urinary tract obstruction, including placement of an internal ureteral stent or nephrostomy, was defined as having a functional ipsilateral kidney. Patients without information on The urinary tract function status were excluded from this study. The 24hCCr, C-G, and the Japanese estimated GFR equation, which originated from the MDRD equation recommended by the Japanese Society of Nephrology (eGFR) [22], were compared for GFR estimation before chemotherapies. The criterion of pretreatment eGFR $\geq 60 \mathrm{~mL} / \mathrm{min} / 1.73 \mathrm{~m}^{2}$ was used to define cisplatin eligibility.

The decision to reduce the dose was made by the physician who treated each patient. Only dose reductions of cisplatin were evaluated in this study; however, data on skipped doses were included for all agents. Serum creatinine levels and eGFR, measured during chemotherapy, were included for the morning of day one (pre-), the day of the maximum level of creatinine (max-), and day 22 (post-) until the fourth course. The data after the fifth course of first-line cisplatin-based chemotherapy was not evaluated in this study. Investigators reported the observed data, including the values of serum creatinine levels, into the website system following first-line chemotherapy, retrospectively.

The chi-square test was used to compare the proportions of clinical parameters between patients with the bilateral and/or the solitary-functioning kidney. A oneway repeated measures analysis of variance (ANOVA)- covariance model and Student's t-test were used to determine the between-group differences and the within-group changes over time, respectively. All statistical analyses were performed using SPSS software, version 22.0 (IBM Corp., Armonk, NY, USA), and $P$-values of $<0.05$ were considered significant.

\section{Results \\ Determination of the urinary tract function status}

According to the criteria described above for the urinary tract function status, regarding nephroureterectomy, hydronephrosis, and relief of the upper urinary tract obstruction, 128 (52.5\%) and 116 (47.5\%) patients were defined as having bilateral and solitary-functioning kidneys, respectively. Nephroureterectomy and relief of upper urinary tract obstruction, including the placement of an internal ureteral stent or nephrostomy, was performed in $49(20.0 \%)$ and $60(24.5 \%)$ patients, respectively. Hydronephroses were left untreated prior to the initiation of chemotherapy in 16 (6.6\%) patients. The urinary tract function status of all the 244 patients is listed in Table 1.

\section{Comparison of the methods to estimate GFR}

The estimated $24 \mathrm{hCCr}$ test was performed in 188 (77.0\%) patients before initiation of chemotherapy. Using results from the $24 \mathrm{hCCr}$ test, 19 (22.1\%) and 55 (57.9\%) patients were diagnosed as cisplatin-ineligible with bilateral and solitary-functioning kidneys, respectively, while eGFR results defined $45(35.2 \%)$ and 80 (69.0\%) patients as cisplatin-ineligible with bilateral and solitary-functioning kidneys, respectively. The proportion of patients defined as cisplatin-ineligible was significantly higher when using eGFR results versus $24 \mathrm{hCCr}$ results $(p=0.040)$. Furthermore, the proportion of cisplatin-ineligible patients who had a solitary-functioning kidney was significantly higher than that of patients with bilateral-functioning kidneys, using both the $24 \mathrm{hCCr}$ and the eGFR tests $(p<0.010$ and $p<0.010$; Fig. 1a). The $24 \mathrm{hCCr}$ and eGFR tests were significantly correlated in patients with bilateral and solitaryfunctioning kidneys $\left(\mathrm{r}^{2}=0.351, p<0.001\right.$ and $\mathrm{r}^{2}=0.402$, $p<0.001$; Fig. 1b, c, respectively).

A total of 244 patients were divided into four groups according to their urinary tract functioning status and eGFR results as listed in Table 1, including bilateral-functioning kidneys with pretreatment eGFR $\geq 60 \mathrm{~mL} / \mathrm{min} / 1.73 \mathrm{~m}^{2}$ group $(n=83,34.0 \%)$; a solitaryfunctioning kidney with pretreatment eGFR $\geq 60$ $\mathrm{mL} / \mathrm{min} / 1.73 \mathrm{~m}^{2}$ group $(n=36,14.8 \%)$; bilateralfunctioning kidneys with pretreatment eGFR $<60 \mathrm{~mL} /$ $\min / 1.73 \mathrm{~m}^{2}$ group $(n=45,18.4 \%)$; and a solitaryfunctioning kidney with pretreatment eGFR $<60 \mathrm{~mL} /$ $\min / 1.73 \mathrm{~m}^{2}$ group $(n=80,32.8 \%)$. 
Table 1 Determination of the urinary tract functioning status and pretreatment eGFR of the 244 patients who underwent cisplatinbased chemotherapies

\begin{tabular}{|c|c|c|c|c|}
\hline & \multicolumn{2}{|c|}{$\begin{array}{l}\text { Pretreatment eGFR } \\
\geq 60 \mathrm{~mL} / \mathrm{min} / 1.73 \mathrm{~m}^{2}\end{array}$} & \multicolumn{2}{|c|}{$\begin{array}{l}\text { Pretreatment eGFR } \\
<60 \mathrm{~mL} / \mathrm{min} / 1.73 \mathrm{~m}^{2}\end{array}$} \\
\hline & $\begin{array}{l}\text { Bilateral } \\
\text { functioning } \\
\text { kidneys } \\
(n=83)\end{array}$ & $\begin{array}{l}\text { Solitary } \\
\text { functioning } \\
\text { kidney } \\
(n=36)\end{array}$ & $\begin{array}{l}\text { Bilateral } \\
\text { functioning } \\
\text { kidneys } \\
(n=45)\end{array}$ & $\begin{array}{l}\text { Solitary } \\
\text { functioning } \\
\text { kidney } \\
(n=80)\end{array}$ \\
\hline \multicolumn{5}{|l|}{ Bilateral functoinal kidneys status } \\
\hline BC with bilateral intact kidneys & $63(75.9 \%)$ & - & $23(51.2 \%)$ & - \\
\hline BC with an unilateral nephrostomy & $4(4.8 \%)$ & - & $9(20.0 \%)$ & - \\
\hline UTUC without nephroureterectomy or hydronephrosis & $11(13.3 \%)$ & - & $11(24.4 \%)$ & - \\
\hline UTUC with an ipsilateral nephrostomy & $2(2.4 \%)$ & - & $1(2.2 \%)$ & - \\
\hline BC + UTUC without nephroureterectomy or hydronephrosis & $3(3.6 \%)$ & - & $1(2.2 \%)$ & - \\
\hline \multicolumn{5}{|l|}{ Solitary functional kidney status } \\
\hline UTUC after nephroureterectomy & - & $7(19.4 \%)$ & - & $37(46.4 \%)$ \\
\hline UTUC without nephroureterectomy with an ipsilateral & - & $11(30.5 \%)$ & - & $22(27.5 \%)$ \\
\hline UTUC in the solitary kidney without hydronephroisis & - & $1(2.7 \%)$ & - & $2(2.5 \%)$ \\
\hline UTUC in the solitary kidney with the ipsilateral nephrostomy & - & $0(0.0 \%)$ & - & $1(1.2 \%)$ \\
\hline BC with an unilateral hydroneohrosis & - & $7(19.4 \%)$ & - & $5(6.2 \%)$ \\
\hline BC with bilateral hydronephroses with unilateral nephrostomy & - & $2(5.6 \%)$ & - & $8(10.0 \%)$ \\
\hline BC with a solitary kidney & - & $3(8.4 \%)$ & - & $1(1.2 \%)$ \\
\hline BC + UTUC after an unilateral nephroureterectomy & - & $3(8.4 \%)$ & - & $2(2.5 \%)$ \\
\hline BC + UTUC with an unilateral hydronephrosis & - & $2(5.6 \%)$ & - & $2(2.5 \%)$ \\
\hline
\end{tabular}

$B C$ bladder cancer, UTUC upper urinary tract urothelial cancer

\section{Comparisons of the patient comorbidity, chemotherapy regimen, dose- reduction, and skipped administration}

The demographic data of the four groups at the beginning of chemotherapy treatment is listed in Table 2. The proportion of patients $<70$ years of age with a solitaryfunctioning kidney was significantly higher than that of those with bilateral-functioning kidneys, for all patients and for patients with pretreatment eGFR $\geq 60 \mathrm{~mL} / \mathrm{min} /$ $1.73 \mathrm{~m}^{2}$ ( $p=0.016$ and $p=0.039$, respectively). The proportion of patients with a solitary-functioning kidney who had lung or liver metastasis was significantly higher than that of patients with bilateral-functioning kidneys with pretreatment eGFR $\geq 60 \mathrm{~mL} / \mathrm{min} / 1.73 \mathrm{~m}^{2}$ (both $p=0.018$ ). The proportion of patients with bilateral-functioning kidneys and lymph node metastasis was significantly higher than patients with a solitary-functioning kidney with pretreatment eGFR $<60 \mathrm{~mL} / \mathrm{min} / 1.73 \mathrm{~m}^{2}(p=0.010$; Table 2). No significant differences were observed in the proportion of medical comorbidities between bilateral and solitaryfunctioning kidney patients with pretreatment eGFR $\geq 60$ or $<60 \mathrm{~mL} / \mathrm{min} / 1.73 \mathrm{~m}^{2}$.

No significant differences were observed in the selection of chemotherapy regimens between patients with the bilateral and solitary-functioning kidneys with respect to those pretreatment eGFR $\geq 60$ or $<60 \mathrm{~mL} / \mathrm{min} /$ $1.73 \mathrm{~m}^{2}$. The proportion of patients whose cisplatin dose was reduced was significantly higher in patients with pretreatment eGFR $<60 \mathrm{~mL} / \mathrm{min} / 1.73 \mathrm{~m}^{2}$ than in those with $\geq 60 \mathrm{~mL} / \mathrm{min} / 1.73 \mathrm{~m}^{2}(p<0.001)$. No significant differences were observed during four courses of cisplatinbased chemotherapy with regards to the patients with cisplatin dose reduction or skipped administration of chemotherapy agents between patients with bilateral and solitary-functioning kidneys with respect to those with pretreatment eGFR $\geq 60$ or $<60 \mathrm{~mL} / \mathrm{min} / 1.73 \mathrm{~m}^{2}$ (Table 3, Additional file 1: Figure S1).

\section{Comparison of nephrotoxicity during cisplatin-based chemotherapy}

In the comparison of nephrotoxicity between the patients with bilateral- and solitary-functioning kidneys, no significant differences were observed in the mean eGFR between both patients with pretreatment eGFR $\geq 60$ and $<60 \mathrm{~mL} / \mathrm{min} / 1.73 \mathrm{~m}^{2}$ (Fig. 2). However, the prevalence of nephrotoxicity with impaired eGFR of $>10 \%$ and $30 \%$ from baseline in the post-third-course of chemotherapy, with rates significantly higher in patients with bilateralfunctioning kidneys than in those with a solitaryfunctioning kidney among patients with pretreatment eGFR $<60 \mathrm{~mL} / \mathrm{min} / 1.73 \mathrm{~m}^{2}(p=0.023$ and $p=0.026$; Table 4, Additional file 2: Figure S2). During all courses of chemotherapy, the prevalence of nephrotoxicity with 

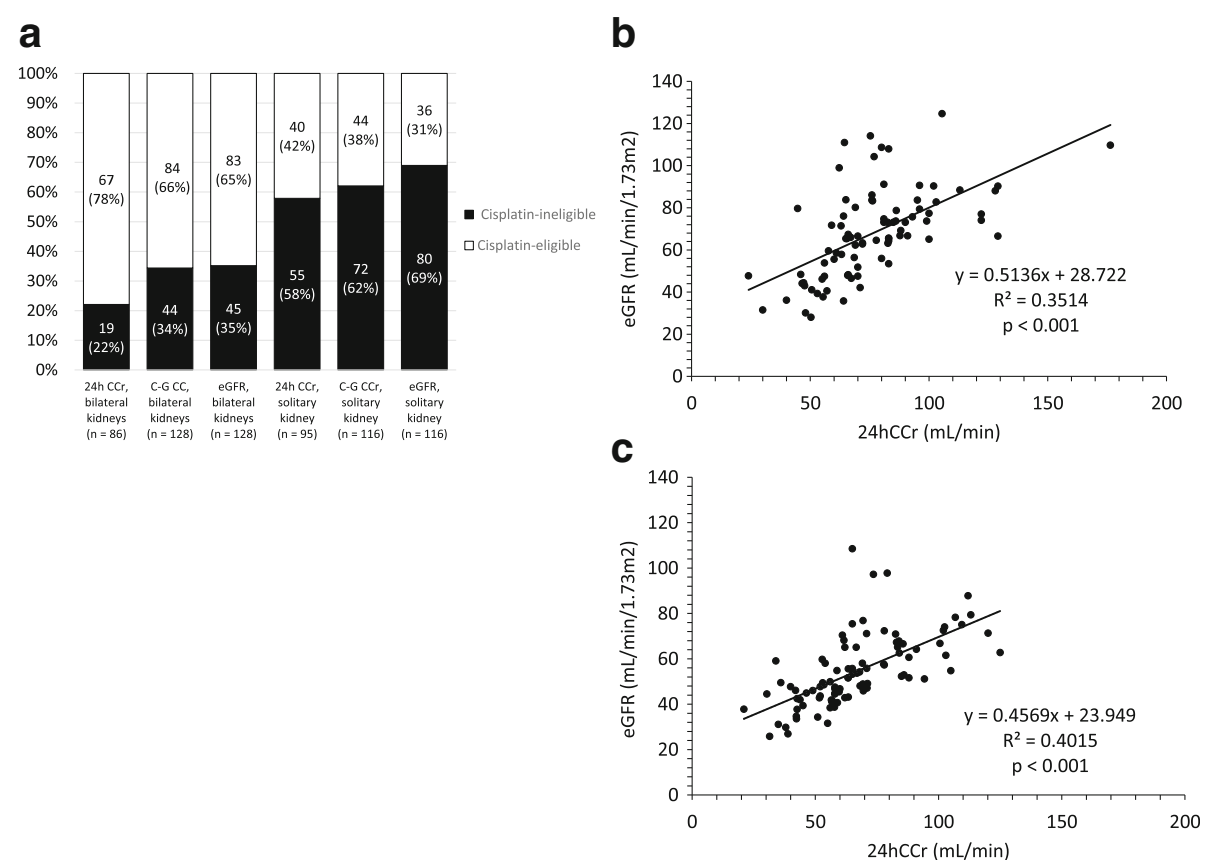

Fig. 1 Comparison of the GFR estimation between $24 \mathrm{hCCr}, \mathrm{C}-\mathrm{G} \mathrm{CCr}$, eGFR, and urinary tract function status. a: Proportions of cisplatin-eligible and ineligible patients based on the methods used to estimate the GFR. 24hCCr estimation was performed in 188 (77.0\%) patients before chemotherapy treatment. The proportion of cisplatin-ineligible patients based on eGFR results was significantly higher than when using $24 \mathrm{hCCr}$ using the threshold of $60 \mathrm{~mL} / \mathrm{min}(p=0.040)$. The proportion of cisplatin-ineligible patients with a solitary-functioning kidney was significantly higher than those with bilateral-functioning kidneys using both $24 \mathrm{hCCr}$ and eGFR tests $(p<0.010$ and $p<0.010)$. b: $24 \mathrm{hCCr}$ and eGFR were significantly correlated in patients with bilateral-functioning kidneys $\left(r^{2}=0.351, p<0.001\right)$. c: $24 \mathrm{hCCr}$ and eGFR were significantly correlated in patients with a solitary-functioning kidney $\left(r^{2}=0.402, p<0.001\right)$

impaired eGFR of $>20 \%$ from baseline were significantly higher in patients with bilateral-functioning kidneys than in those with a solitary-functioning kidney among patients with pretreatment eGFR $<60 \mathrm{~mL} / \mathrm{min} / 1.73 \mathrm{~m}^{2}$ $(p=0.034$; Table 4$)$, whereas no significant difference was observed among patients with pretreatment eGFR $\geq 60 \mathrm{~mL} / \mathrm{min} / 1.73 \mathrm{~m}^{2}$.

In the comparison of nephrotoxicity between patients with pretreatment eGFR $\geq 60$ and $<60 \mathrm{~mL} / \mathrm{min} / 1.73 \mathrm{~m}^{2}$, the prevalence of impaired eGFR of $>10 \%$ from baseline in the post-first to fourth courses in patients with pretreatment eGFR $\geq 60 \mathrm{~mL} / \mathrm{min} / 1.73 \mathrm{~m}^{2}$ was significantly higher than those in patients with pretreatment eGFR $<60 \mathrm{~mL} / \mathrm{min} / 1.73 \mathrm{~m}^{2}(p=0.015, p=0.026, p=0.011$, and $p=0.010$, respectively; Table 4$)$. The prevalence of impaired eGFR of $>20 \%$ from baseline in the post-third and fourth courses in patients with pretreatment eGFR $\geq 60 \mathrm{~mL} / \mathrm{min} / 1.73 \mathrm{~m}^{2}$ was significantly higher than those in patients with pretreatment eGFR $<60 \mathrm{~mL} / \mathrm{min} / 1.73 \mathrm{~m}^{2}$ $(p=0.015$ and $p=0.028$; Table 4$)$. Furthermore, the prevalence of impaired eGFR of $>30 \%$ from baseline at the post-fourth course in patients with pretreatment eGFR $\geq 60 \mathrm{~mL} / \mathrm{min} / 1.73 \mathrm{~m}^{2}$ was significantly higher than that of patients with pretreatment eGFR $<60 \mathrm{~mL} /$ $\min / 1.73 \mathrm{~m}^{2}(p=0.012$; Table 4$)$. During all courses of chemotherapy, the prevalence of impaired eGFR of > $10 \%$ and $30 \%$ from baseline in patients with pretreatment eGFR $\geq 60 \mathrm{~mL} / \mathrm{min} / 1.73 \mathrm{~m}^{2}$ was significantly higher than those in patients with pretreatment eGFR $<60 \mathrm{~mL} / \mathrm{min} / 1.73 \mathrm{~m}^{2}(p<0.001$ and $p=0.036$; Table 4$)$. No patients required hemodialysis.

\section{Discussion}

In advanced UTUC patients following nephroureterectomy, the proportion of cisplatin-ineligible patients is reportedly $78-81 \%$, and there is often a therapeutic dilemma in the chemotherapy for these patients [17]. In total, 37 of the $44(78.7 \%)$ patients who underwent nephroureterectomy in this study were categorized into the group of eGFR $<60 \mathrm{~mL} / \mathrm{min} / 1.73 \mathrm{~m}^{2}$. Although carboplatin-based combination chemotherapies have been the most favored regimens in these kinds of patients, cisplatin-based chemotherapies were selected in this study at the discretion of individual institutes, likely because of the evidence of the better outcomes of cisplatin-based chemotherapies in cisplatin-eligible advanced UC [6]. However, the nephrotoxicity of cisplatinbased chemotherapy in patients with an intact solitary kidney has not been extensively investigated. The present study is the first retrospective study comparing 
Table 2 Demographic data of analyzed 244 patients who underwent cisplatin-based chemotherapies

\begin{tabular}{|c|c|c|c|c|c|c|c|c|c|c|}
\hline & & \multicolumn{3}{|l|}{ All patients } & \multicolumn{3}{|c|}{$\begin{array}{l}\text { Pretreatment eGFR } \\
\geq 60 \mathrm{~mL} / \mathrm{min} / 1.73 \mathrm{~m}^{2} \\
\end{array}$} & \multicolumn{3}{|c|}{$\begin{array}{l}\text { Pretreatment eGFR } \\
<60 \mathrm{~mL} / \mathrm{min} / 1.73 \mathrm{~m}^{2}\end{array}$} \\
\hline & & $\begin{array}{l}\text { Pretreatment } \\
\text { eGFR } \geq 60 \\
\mathrm{~mL} / \mathrm{min} / \\
1.73 \mathrm{~m}^{2} \\
(n=119)\end{array}$ & $\begin{array}{l}\text { Pretreatment } \\
\text { eGFR }<60 \\
\mathrm{~mL} / \mathrm{min} / \\
1.73 \mathrm{~m}^{2} \\
(n=125)\end{array}$ & $p$ & $\begin{array}{l}\text { Bilateral } \\
\text { functioning } \\
\text { kidneys } \\
(n=83)\end{array}$ & $\begin{array}{l}\text { Solitary } \\
\text { functioning } \\
\text { kidney } \\
(n=36)\end{array}$ & $p$ & $\begin{array}{l}\text { Bilateral } \\
\text { functioning } \\
\text { kidneys } \\
(n=45)\end{array}$ & $\begin{array}{l}\text { Solitary } \\
\text { functioning } \\
\text { kidney } \\
(n=80)\end{array}$ & $p$ \\
\hline \multirow[t]{2}{*}{$\overline{\text { Age }}$} & $<70$ & $78(65.5 \%)$ & $63(50.4 \%)$ & 0.016 & $49(58.9 \%)$ & 29 (80.5\%) & 0.039 & $20(44.4 \%)$ & $43(53.7 \%)$ & 0.32 \\
\hline & $\geq 70$ & $41(34.4 \%)$ & $62(49.6 \%)$ & & $34(41.1 \%)$ & 7 (19.5\%) & & $25(55.6 \%)$ & $37(46.3 \%)$ & \\
\hline \multirow[t]{2}{*}{ PS } & $0-1$ & 111 (93.2\%) & $117(93.6 \%)$ & 0.91 & 77 (92.7\%) & 34 (94.4\%) & 0.94 & $42(93.3 \%)$ & 75 (93.8\%) & 0.083 \\
\hline & $2-4$ & $8(6.7 \%)$ & $8(6.4 \%)$ & & $6(7.3 \%)$ & $2(5.6 \%)$ & & $3(6.7 \%)$ & $5(6.2 \%)$ & \\
\hline \multirow[t]{2}{*}{ Sex } & Male & $86(72.3 \%)$ & 87 (69.6\%) & 0.64 & $61(73.5 \%)$ & 25 (69.4\%) & 0.65 & $32(71.1 \%)$ & $55(68.7 \%)$ & 0.78 \\
\hline & Female & $33(27.7 \%)$ & 38 (30.4\%) & & $22(26.5 \%)$ & $11(30.6 \%)$ & & $13(28.9 \%)$ & $25(31.3 \%)$ & \\
\hline \multirow[t]{5}{*}{ Comorbidities } & yes & $15(12.6 \%)$ & 17 (14.2\%) & 0.81 & $13(15.7 \%)$ & $2(5.6 \%)$ & 0.12 & $8(17.8 \%)$ & $9(11.2 \%)$ & 0.36 \\
\hline & no / unknown & $104(87.4 \%)$ & $108(86.4 \%)$ & & $70(84.3 \%)$ & 34 (94.4\%) & & $37(82.2 \%)$ & $71(88.8 \%)$ & \\
\hline & $\mathrm{DM}$ & $3(2.5 \%)$ & $4(3.2 \%)$ & & $2(2.4 \%)$ & $1(2.7 \%)$ & & $2(4.4 \%)$ & $2(2.4 \%)$ & \\
\hline & Glomerulonephritis & $1(0.8 \%)$ & $1(0.8 \%)$ & & $1(1.2 \%)$ & $0(0.0 \%)$ & & $0(0.0 \%)$ & $1(1.2 \%)$ & \\
\hline & Others & $11(9.2 \%)$ & $12(9.6 \%)$ & & $10(12.1 \%)$ & $1(2.7 \%)$ & & $6(13.3 \%)$ & $6(7.5 \%)$ & \\
\hline \multirow{3}{*}{$\begin{array}{l}\text { Cancer } \\
\text { location }\end{array}$} & $\mathrm{BC}$ & $79(66.5 \%)$ & $46(36.8 \%)$ & $<0.001$ & $67(80.7 \%)$ & $12(33.3 \%)$ & $<0.001$ & $32(71.1 \%)$ & $14(17.5 \%)$ & $<0.001$ \\
\hline & UTUC & $32(26.8 \%)$ & $74(59.2 \%)$ & & $13(15.7 \%)$ & 19 (52.8\%) & & $12(26.7 \%)$ & $62(77.5 \%)$ & \\
\hline & $\mathrm{BC}+$ UTUC & $8(6.7 \%)$ & $5(4.0 \%)$ & & $3(3.6 \%)$ & $5(13.9 \%)$ & & $1(2.2 \%)$ & $4(5.0 \%)$ & \\
\hline \multirow[t]{4}{*}{ Surgery } & No surgery & $85(71.5 \%)$ & $73(58.4 \%)$ & 0.033 & $63(75.9 \%)$ & $22(61.1 \%)$ & $<0.001$ & $38(84.4 \%)$ & $35(43.7 \%)$ & $<0.001$ \\
\hline & Cystectomy & $25(21.0 \%)$ & $14(11.2 \%)$ & & $20(24.1 \%)$ & $5(13.9 \%)$ & & $7(15.6 \%)$ & 7 (8.8\%) & \\
\hline & Nephroureterectomy & $7(5.8 \%)$ & 37 (29.6\%) & & $0(0.0 \%)$ & 7 (19.4\%) & & $0(0.0 \%)$ & 37 (46.3\%) & \\
\hline & $\begin{array}{l}\text { Cystectomy }+ \\
\text { nephroureterectomy }\end{array}$ & $2(1.7 \%)$ & $1(0.8 \%)$ & & $0(0.0 \%)$ & $2(5.6 \%)$ & & $0(0.0 \%)$ & $1(1.2 \%)$ & \\
\hline \multirow[t]{5}{*}{ Metastatic site } & Lymph node & 77 (64.7\%) & $68(54.4 \%)$ & 0.10 & $55(66.2 \%)$ & $22(61.1 \%)$ & 0.58 & $33(73.3 \%)$ & $35(43.8 \%)$ & 0.001 \\
\hline & Lung & $41(34.5 \%)$ & 45 (36.0\%) & 0.80 & $23(12.1 \%)$ & $18(50.0 \%)$ & 0.018 & $16(35.6 \%)$ & $29(36.3 \%)$ & 0.94 \\
\hline & Liver & $24(20.2 \%)$ & $18(14.4 \%)$ & 0.23 & $12(14.5 \%)$ & $12(33.3 \%)$ & 0.018 & $6(13.3 \%)$ & $12(15.0 \%)$ & 0.79 \\
\hline & Bone & $22(18.5 \%)$ & $17(13.6 \%)$ & 0.29 & $13(15.7 \%)$ & $9(25.0 \%)$ & 0.23 & $6(13.3 \%)$ & $11(13.7 \%)$ & 0.95 \\
\hline & Others & $28(23.5 \%)$ & 32 (25.6\%) & 0.70 & 15 (18.1\%) & 13 (36.1\%) & 0.033 & $9(20.0 \%)$ & 23 (28.7\%) & 0.28 \\
\hline
\end{tabular}

the nephrotoxicity between bilateral- and solitaryfunctioning kidneys in CKD patients during cisplatinbased chemotherapies.

In the evaluation of the mean value of eGFR in this study, the kidney function did not deteriorate during four courses. Moreover, the mean kidney function between patients with bilateral- and solitary-functioning kidneys did not significantly differ in both patients with pretreatment eGFR $\geq 60$ and $<60 \mathrm{~mL} / \mathrm{min} / 1.73 \mathrm{~m}^{2}$. However, there should be a significant bias noted in that the patients who did not continue the chemotherapy due to nephrotoxicity were excluded from the next course in the evaluation of the mean value of eGFR. Therefore, we focused more on the nephrotoxicity of individual patients; indeed, the nephrotoxicity was more frequently observed in patients with bilateral-functioning kidneys than in those with a solitary-functioning kidney in patients with pretreatment eGFR $<60 \mathrm{~mL} / \mathrm{min} / 1.73 \mathrm{~m}^{2}$. The details of cisplatin-based chemotherapy were almost not found to be significantly different between groups based on the selection of chemotherapy regimen, reduction of cisplatin dose and/or the requirement to skip administration of the chemotherapy agents. Although the difference was slight, our data suggest that kidney function is more likely to be injured by cisplatin-based chemotherapies in patients with bilateral-functioning kidneys than in those with a solitary-functioning kidney.

The reason for our results may be that the microstructures of the nephrons in CKD-S patients following contralateral nephroureterectomy or hydronephrosis are less deteriorated and more resistant to chemotherapy than those in CKD-M patients with bilateral-functioning kidneys. Although the difference was not significant, comorbidities were more frequently 
Table 3 Comparison of the proportion of the selected chemotherapy regimens, dose-reduction, and skip administration

\begin{tabular}{|c|c|c|c|c|c|c|c|c|c|c|}
\hline & & \multicolumn{3}{|l|}{ All patients } & \multicolumn{3}{|c|}{$\begin{array}{l}\text { Cisplatin-eligible } \\
\left(\text { eGFR } \geq 60 \mathrm{~mL} / \mathrm{min} / 1.73 \mathrm{~m}^{2}\right)\end{array}$} & \multicolumn{3}{|c|}{$\begin{array}{l}\text { Cisplatin-ineligible } \\
(\text { eGFR < } 60 \text { mL/min/1.73 m2) }\end{array}$} \\
\hline & & $\begin{array}{l}\text { Cisplatin-eligible } \\
(n=119)\end{array}$ & $\begin{array}{l}\text { Cisplatin-ineligible } \\
(n=125)\end{array}$ & $p$ & $\begin{array}{l}\text { Bilateral } \\
\text { functioning } \\
\text { kidneys } \\
(n=83)\end{array}$ & $\begin{array}{l}\text { Solitary } \\
\text { functioning } \\
\text { kidney } \\
(n=36)\end{array}$ & $p$ & $\begin{array}{l}\text { Bilateral } \\
\text { functioning } \\
\text { kidneys } \\
(n=45)\end{array}$ & $\begin{array}{l}\text { Solitary } \\
\text { functioning } \\
\text { kidney } \\
(n=80)\end{array}$ & $p$ \\
\hline \multirow[t]{4}{*}{ Chemotherapy } & GC & $48(40.3 \%)$ & $55(44.0 \%)$ & 0.56 & $35(42.2 \%)$ & $13(36.2 \%)$ & 0.530 & $24(53.3 \%)$ & 31 (38.8\%) & 0.160 \\
\hline & MVAC & $52(43.6 \%)$ & 46 (36.8\%) & 0.27 & $37(44.6 \%)$ & $15(41.6 \%)$ & 0.760 & $14(31.1 \%)$ & $32(40.0 \%)$ & 0.110 \\
\hline & MEC & $16(13.4 \%)$ & 19 (15.2\%) & 0.70 & $9(10.8 \%)$ & $7(19.4 \%)$ & 0.210 & $4(8.9 \%)$ & $15(18.7 \%)$ & 0.140 \\
\hline & $\begin{array}{l}\text { Gemcitabine } \\
+ \text { Cisplatin + } \\
\text { Docetaxel }\end{array}$ & $3(2.5 \%)$ & $5(4.0 \%)$ & 0.51 & $2(2.4 \%)$ & $1(2.8 \%)$ & 0.900 & $3(6.7 \%)$ & $2(2.5 \%)$ & 0.850 \\
\hline \multicolumn{11}{|c|}{ Cisplatin dose reduction } \\
\hline all courses & Yes & $10(8.4 \%)$ & $42(33.6 \%)$ & $<0.001$ & $6(7.2 \%)$ & $4(11.1 \%)$ & 0.480 & $16(35.5 \%)$ & $26(32.5 \%)$ & 0.730 \\
\hline \multirow[t]{3}{*}{ 1st course } & Yes & 9/119 (7.5\%) & $48 / 125(38.4 \%)$ & $<0.001$ & $6 / 83(7.2 \%)$ & $3 / 36(8.3 \%)$ & 0.834 & $16 / 45(35.5 \%)$ & $32 / 80$ (39.9\%) & 0.623 \\
\hline & $99-80 \%$ & 8/119 (6.7\%) & $15 / 125(12.0 \%)$ & 0.158 & $5 / 83(6.0 \%)$ & $3 / 36(8.3 \%)$ & 0.644 & $5 / 45(11.1 \%)$ & 10/80 (12.5\%) & 0.810 \\
\hline & $<80 \%$ & $1 / 119(0.8 \%)$ & $33 / 125$ (26.4\%) & $<0.001$ & $1 / 83(1.2 \%)$ & $0 / 36(0.0 \%)$ & 0.508 & $11 / 45$ (24.4\%) & 22/80 (27.5\%) & 0.709 \\
\hline \multirow[t]{3}{*}{ 2nd course } & Yes & 8/104 (7.7\%) & $39 / 110$ (35.3\%) & $<0.001$ & $5 / 72(8.3 \%)$ & $3 / 32(9.3 \%)$ & 0.667 & 13/42 (30.8\%) & 26/68 (38.1\%) & 0.437 \\
\hline & $99-80 \%$ & 7/104 (6.7\%) & 9/110 (8.1\%) & 0.686 & 4/72 (6.9\%) & $3 / 32(9.3 \%)$ & 0.473 & $2 / 42(4.7 \%)$ & 7/68 (10.2\%) & 0.303 \\
\hline & $<80 \%$ & $1 / 104(1.0 \%)$ & $30 / 110$ (27.2\%) & $<0.001$ & 1/72 (1.4\%) & 0/32 (0.0\%) & 0.500 & $11 / 42(26.1 \%)$ & 19/68 (27.9\%) & 0.841 \\
\hline \multirow[t]{3}{*}{ 3rd course } & Yes & 4/81 (4.9\%) & 23/82 (28.0\%) & $<0.001$ & $2 / 54(3.8 \%)$ & $2 / 27(7.4 \%)$ & 0.468 & 6/24 (24.9\%) & 17/58 (29.2\%) & 0.690 \\
\hline & $99-80 \%$ & $3 / 81(3.7 \%)$ & $7 / 82(8.5 \%)$ & 0.198 & 1/54 (1.9\%) & 2/27 (7.4\%) & 0.212 & $1 / 24(4.1 \%)$ & 6/58 (10.3\%) & 0.362 \\
\hline & $<80 \%$ & $1 / 81(1.2 \%)$ & 16/82 (19.5\%) & $<0.001$ & $1 / 54(1.9 \%)$ & $0 / 27(0.0 \%)$ & 0.476 & $5 / 24(20.8 \%)$ & 11/58 (18.9\%) & 0.846 \\
\hline \multirow[t]{3}{*}{ 4th course } & Yes & $2 / 59(3.4 \%)$ & 15/59 (25.4\%) & $<0.001$ & 0/39 (0.0\%) & $2 / 20(10.0 \%)$ & 0.044 & $4 / 20(20.0 \%)$ & 12/39 (30.7\%) & 0.378 \\
\hline & $99-80 \%$ & $2 / 59(3.4 \%)$ & $6 / 59(10.2 \%)$ & 0.142 & $0 / 39(0.0 \%)$ & $2 / 20(10.0 \%)$ & 0.044 & $1 / 20(5.0 \%)$ & $5 / 39(12.8 \%)$ & 0.346 \\
\hline & $<80 \%$ & $0 / 59(0.0 \%)$ & 9/59 (15.2\%) & $<0.001$ & $0 / 39(0.0 \%)$ & $0 / 20(0.0 \%)$ & 1.000 & $3 / 20(15.0 \%)$ & 7/39 (17.9\%) & 0.775 \\
\hline \multicolumn{11}{|l|}{ Skip } \\
\hline \multirow[t]{2}{*}{ all courses } & Yes & 65 (54.6\%) & 70 (56.0\%) & 0.83 & 49 (59.0\%) & $16(44.4 \%)$ & 0.140 & $23(51.1 \%)$ & 47 (58.8\%) & 0.400 \\
\hline & No & $54(45.3 \%)$ & 55 (44.0\%) & & 34 (40.9\%) & $20(55.6 \%)$ & & 22 (48.9\%) & $33(41.2 \%)$ & \\
\hline \multirow[t]{3}{*}{ 1st course } & day 8 & $8(6.7 \%)$ & 15 (12.0\%) & 0.16 & 7 (8.4\%) & $1(2.7 \%)$ & 0.250 & 4 (8.9\%) & 11 (13.7\%) & 0.420 \\
\hline & day 15 & 54 (45.3\%) & 54 (43.2\%) & 0.73 & 40 (48.1\%) & 14 (38.9\%) & 0.340 & 17 (37.7\%) & 37 (46.3\%) & 0.350 \\
\hline & day 22 & $8(6.7 \%)$ & 13 (10.4\%) & 0.30 & $6(7.2 \%)$ & $2(5.6 \%)$ & 0.730 & $4(4.4 \%)$ & 9 (11.3\%) & 0.680 \\
\hline
\end{tabular}

$B C$ bladder cancer, UTUC upper urinary tract urothelial cancer

observed in patients with bilateral-functioning kidneys than in those with a solitary-functioning kidney. Histories of diabetes mellitus and cardiovascular disease were found to be significant risk factors to predict severe acute kidney injury induced by cisplatin-based chemotherapy in a previous evaluation of 1721 cancer patients [23]. Although the mean body mass index was not significantly different between the groups in this series, there is a possibility that the potential deterioration of the kidney such as smoking status, hypertension, or hyperuricemia might be more prevalent in patients with bilateral-functioning kidneys than in those with a solitary-functioning kidney. The differences of these factors were not obvious because of the retrospective study.
Another finding in this retrospective study was that patients with impaired kidney function were more frequently observed in patients with pretreatment eGFR $\geq 60$ than in $<60 \mathrm{~mL} / \mathrm{min} / 1.73 \mathrm{~m}^{2}$, probably because of the frequent dose reductions in patients with pretreatment eGFR < $60 \mathrm{~mL} / \mathrm{min} / 1.73 \mathrm{~m}^{2}$. Moreover, the prevalence of the nephrotoxicity increased as chemotherapy courses progressed, during the four courses in patients with pretreatment eGFR $\geq 60 \mathrm{~mL} / \mathrm{min} / 1.73 \mathrm{~m}^{2}$, with an $8.4 \%$ reduction in the dose of cisplatin. However, the prevalence was not increased in patients with pretreatment eGFR $<60 \mathrm{~mL} /$ $\mathrm{min} / 1.73 \mathrm{~m}^{2}$ with a $33.6 \%$ reduction in the dose of cisplatin. The effectiveness and the safety of cisplatin dose reduction in patients with pretreatment eGFR $<60 \mathrm{~mL} /$ $\mathrm{min} / 1.73 \mathrm{~m}^{2}$ has not been clearly elucidated because of 


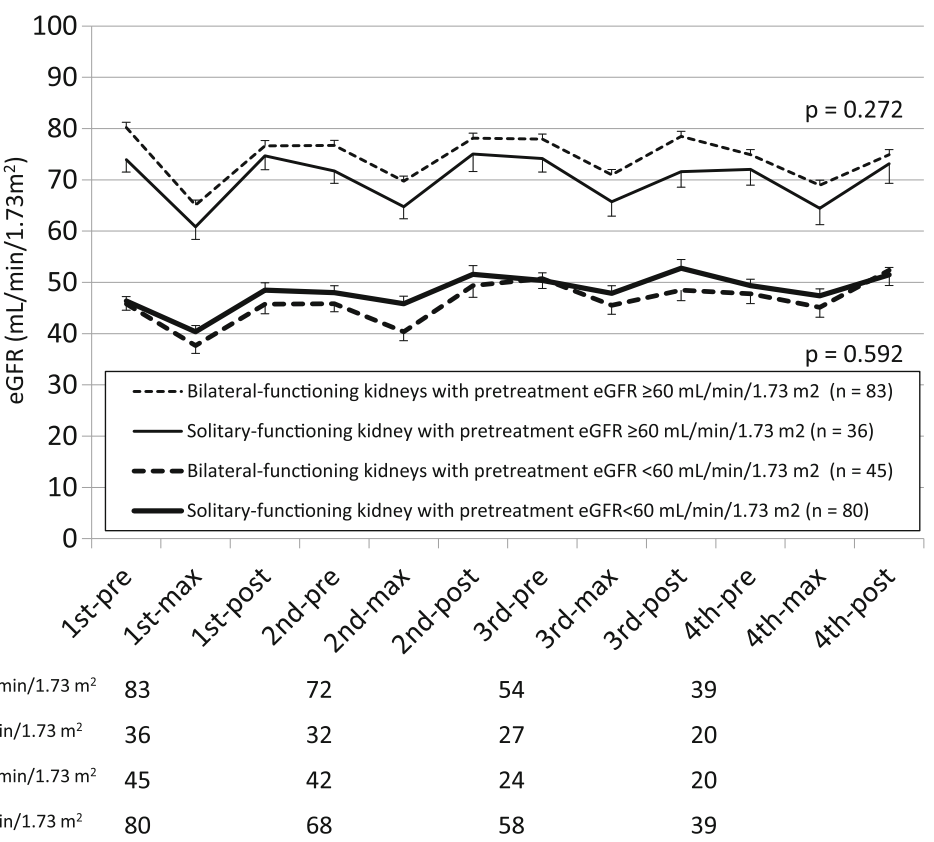

Fig. 2 Comparison of the mean eGFR value during cisplatin-based chemotherapies between bilateral and solitary-functioning kidneys, in patients with eGFR $\geq 60$ and $<60 \mathrm{~mL} / \mathrm{min} / 1.73 \mathrm{~m}^{2}$. No significant differences were observed in the mean eGFR between patients with bilateral and solitary-functioning kidneys

the ethical difficulties surrounding conducting such a prospective study [12, 24]. Although the one-year overall survival of the patients treated with a reduced dose of cisplatin-based chemotherapy was significantly lower than that of those treated with the standard dose in the CURE study using the same patient series [13], the results of this study demonstrated the safety of cisplatin dose reduction for cisplatin-ineligible patients in preventing nephrotoxicity.

Even considering our study results, cisplatin-based chemotherapy is not always safe and is not recommended for all the CKD-S patients with a solitaryfunctioning kidney with pretreatment eGFR $<60 \mathrm{~mL} /$ $\min / 1.73 \mathrm{~m}^{2}$. However, the threshold and method to determine cisplatin-eligibility for patients with marginal kidney function are still controversial. Previous studies have shown about two-thirds of discordance in three methods of GFR estimation [5]. From the current study results, cisplatin-based chemotherapies could be recommended at least in CKD-S patients with marginal kidney function, such as around $10 \%$ of patients who are categorized in pretreatment $24 \mathrm{hCCr}>60 \mathrm{~mL} / \mathrm{min}$, as well as eGFR $<60 \mathrm{~mL} / \mathrm{min} / 1.73 \mathrm{~m}^{2}$, as shown in Fig. 1. For patients with pretreatment eGFR of $50-60 \mathrm{~mL} /$ $\mathrm{min} / 1.73 \mathrm{~m}^{2}, \quad 15 / 16 \quad(93.7 \%)$ and $23 / 26 \quad(88.5 \%)$ patients received a standard dose of cisplatin in bilateral- and solitary-functioning kidney patients, respectively. The prevalence of nephrotoxicity by more than $30 \%$ impaired kidney function during all courses of chemotherapy was $2 / 16(12.5 \%)$ and $3 / 24(12.5 \%)$, respectively.

There are several considerable limitations in this study. First, this study is a retrospective evaluation, and chemotherapy regimens or dose reductions for each cisplatin-ineligible patient were carefully selected under the discretion at each institute before initiation of the treatments. Patients with lower kidney function, higher age, and/or lower performance status received alternative regimens with or without platinum agents. In actuality, 90 of the 345 (26.1\%) patients evaluated in the CURE study group, including 70 cisplatin-ineligible patients, did not receive cisplatinbased chemotherapies and of them, 57 received other platinum-based combination chemotherapy regimens consisting of carboplatin or nedaplatin, while 33 received chemotherapy without platinum agents. Second, only cisplatin but not methotrexate was considered as the nephrotoxic agent in this study. Third, the use of a detailed objective scoring system of medical comorbidities, such as the Charlson Comorbidity Index, was not evaluated in this study. Lastly, not only patients with nephroureterectomy but also patients who had unilateral hydronephrosis or who underwent a relief of the upper urinary tract obstruction were included in the group of patients with a solitary kidney. As such, variations in functional status of the urinary tract in patients with a solitary kidney are also a considerable limitation of this study. 


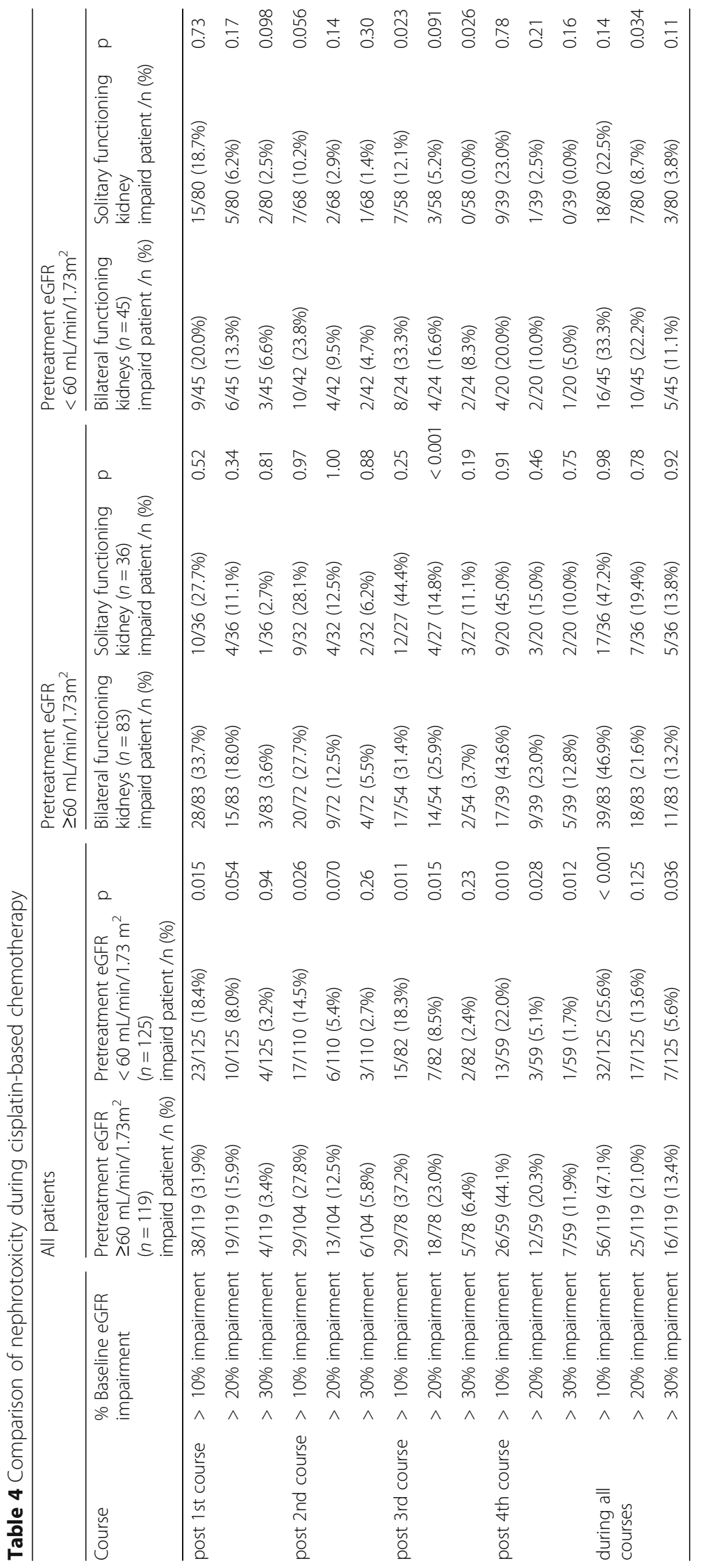




\section{Conclusions}

The results suggest that cisplatin-based chemotherapies may have more nephrotoxicity in patients with bilateral-functioning kidneys than in those with a solitary-functioning kidney. The nephrotoxicity of the chemotherapy may be of increased concern in CKD$M$ patients with bilateral-functioning kidneys than in CKD-S patients with a solitary-functioning kidney.

\section{Additional files}

Additional file 1: Figure S1. Comparison of the number of patients with cisplatin dose-reduction between the four groups during four courses of cisplatin-based chemotherapy. A: First course, B: Second course, C: Third course, D: Fourth course. (PDF $104 \mathrm{~kb}$ )

Additional file 2: Figure S2. Comparison of the number of patients with nephrotoxicity between the four groups during four courses of cisplatin-based chemotherapy. A: Post first course, B: Post second course, C: Post third course, D: Post fourth course. (PDF 102 kb)

\section{Abbreviations}

24hCCr: 24 h creatinine clearance; ANOVA: One-way repeated measures analysis of variance; C-G: Cockcroft-Gault formula; CKD-M: Medically-induced chronic kidney disease; CKD: Chronic kidney disease; CKD-S: Surgicallyinduced chronic kidney disease; eGFR: Estimated glomerular filtration rate; GC: Gemcitabine and cisplatin; GCD: Gemcitabine, cisplatin, and docetaxel; GFR: Glomerular filtration rate; MDRD: Modification of diet in renal disease; MEC: Methotrexate, epirubicin, and cisplatin; MVAC: Methotrexate, vinblastine, doxorubicin, and cisplatin; UC: Urothelial carcinoma; UTUC: Upper tract urothelial carcinoma

\section{Acknowledgements}

We thank Koichi Hashimoto and Naoto Keino at Tsukuba Clinical Research \& Development Organization (T-CReDO), University of Tsukuba, for their invaluable assistance.

\section{Funding}

Not applicable.

\section{Availability of data and materials}

All data were collected from medical records at each institution and stored in a secretariat server on the website in the University of Tsukuba. The trial was registered in university hospital medical information network clinical trials registry (UMIN-CTR; \# UMIN000007601) in Japan.

\section{Authors' contributions}

TI performed data collection, statistical analysis, interpretation of results, and writing the manuscript. JM performed data collection and statistical analysis. DI performed data collection and statistical analysis. SN performed data collection and interpretation of results. SK, MS, KM, YS, HK, HW, TN, YM and EK performed data collection in each institute. KF performed data collection and statistical analysis. NK performed data collection and statistical analysis. TH performed interpretation of results. HN performed data collection, interpretation of results, and writing the manuscript. All authors read and approved the final manuscript.

\section{Ethics approval and consent to participate}

The concept of the study was approved by the internal ethical committees at all of the 17 institutions involved.

The explicit name of the committees was followings;

Ethics committee, Akita University Graduate School of Medicine.

Ethics committee, University of Tsukuba Faculty of Medicine.

Ethics committee, Shiga University of Medical Science.

Ethics committee, Kagawa University, Faculty of Medicine.

Ethics committee, Tohoku University Graduate School of Medicine.

Ethics committee, Hyogo College of Medicine.

Ethics committee, Kansai Medical University.
Ethics committee, Faculty of Medicine, University of Miyazaki. Ethics committee, Tokai University School of Medicine. Ethics committee, Keio University School of Medicine. Ethics committee, Kyoto University Graduate School of Medicine. Ethics committee, Ibaraki Prefectural Central Hospital. Ethics committee, Kameda Medical Center.

Ethics committee, International University of Health and Welfare. Ethics committee, Mito Saiseikai General Hospital. Ethics committee, Tsukuba Medical Center Hospital. Ethics committee, Hitachi General Hospital.

\section{Consent for publication}

Informed consent for chemotherapies was obtained from all the patients. Informed consent to participate in the study was not obtained with an opt-out statement on the website of all of the 17 institutions involved because of the retrospective fashion of the study. No patients were 16 years old or below.

\section{Competing interests}

The authors declare that they have no competing interests.

\section{Publisher's Note}

Springer Nature remains neutral with regard to jurisdictional claims in published maps and institutional affiliations.

\section{Author details}

1Department of Urology, Akita University Graduate School of Medicine, Akita 010-8543, Japan. ${ }^{2}$ Department of Urology, Faculty of Medicine, University of Tsukuba, 1-1-1, Tennodai, Tsukuba, Ibaraki 305-8575, Japan. ${ }^{3}$ Department of Urology, Shiga University of Medical Science, Otsu, Shiga 520-2192, Japan. ${ }^{4}$ Department of Urology, Kagawa University, Faculty of Medicine, Takamatsu, Kagawa 761-0701, Japan. ${ }^{5}$ Department of Urology, Tohoku University Graduate School of Medicine, Sendai, Miyagi 980-8575, Japan. ${ }^{6}$ Department of Urology, Hyogo College of Medicine, Nishinomiya, Hyogo 663-8501, Japan. ${ }^{7}$ Department of Urology and Andrology, Kansai Medical University, Hirakata, Osaka 573-1191, Japan. ${ }^{8}$ Department of Urology, Faculty of Medicine, University of Miyazaki, Miyazaki 889-1692, Japan. ${ }^{9}$ Department of Urology, Tokai University School of Medicine, Sagamihara, Kanagawa 259-1193, Japan. ${ }^{10}$ Department of Urology, Keio University School of Medicine, Tokyo 160-8582, Japan. ${ }^{11}$ Department of Urology, Kyoto University Graduate School of Medicine, Kyoto 606-8501, Japan. ${ }^{12}$ Faculty of Medicine, University of Tsukuba, Tsukuba, Ibaraki 305-8575, Japan. ${ }^{13}$ Tsukuba Clinical Research \& Development Organization, University of Tsukuba, Tsukuba, Ibaraki 305-8575, Japan.

Received: 14 April 2017 Accepted: 6 March 2018

Published online: 14 March 2018

\section{References}

1. Loehrer PJ Sr, Einhorn LH, Elson PJ, Crawford ED, Kuebler P, Tannock I, et al. A randomized comparison of cisplatin alone or in combination with methotrexate, vinblastine, and doxorubicin in patients with metastatic urothelial carcinoma: a cooperative group study. J Clin Oncol. 1992;10:1066-73.

2. Sternberg CN, Yagoda A, Scher HI, Watson RC, Geller N, Herr HW, et al. MVAC (methotrexate, vinblastine, doxorubicin and cisplatin) for advanced transitional cell carcinoma of the urothelium. J Urol. 1988;139:461-9.

3. von der Maase H, Hansen SW, Roberts JT, Dogliotti L, Oliver T, Moore MJ, et al. Gemcitabine and cisplatin versus methotrexate, vinblastine, doxorubicin, and cisplatin in advanced or metastatic bladder cancer: results of a large, randomized, multinational, multicenter, phase III study. J Clin Oncol. 2000;18:3068-77.

4. Vaughn DJ. Chemotherapeutic options for cisplatin-ineligible patients with advanced carcinoma of the urothelium. Cancer Treat Rev. 2008:34:328-38.

5. Dash A, Galsky MD, Vickers AJ, Serio AM, Koppie TM, Dalbagni G, et al. Impact of renal impairment on eligibility for adjuvant cisplatin-based chemotherapy in patients with urothelial carcinoma of the bladder. Cancer. 2006;107:506-13.

6. Dogliotti L, Cartenì G, Siena S, Bertetto O, Martoni A, Bono A, et al. Gemcitabine plus cisplatin versus gemcitabine plus carboplatin as first-line chemotherapy in advanced transitional cell carcinoma of the urothelium: results of a randomized phase 2 trial. Eur Urol. 2007;52:134-41. 
7. Bellmunt J, Ribas A, Eres N, Casado S, Albanell J, Baselga J. Carboplatinbased versus cisplatin-based chemotherapy in the treatment of surgically incurable advanced bladder carcinoma. Cancer. 1997;80:1966-72.

8. Nogué-Aliguer M, Carles J, Arrivi A, Juan O, Alonso L, Font A, et al. Gemcitabine and carboplatin in advanced transitional cell carcinoma of the urinary tract: an alternative therapy. Cancer. 2003;97:2180-6.

9. Linardou H, Aravantinos G, Efstathiou E, Kalofonos C, Anagnostopoulos A, Deliveliotis C, et al. Gemcitabine and carboplatin combination as first-line treatment in elderly patients and those unfit for cisplatin-based chemotherapy with advanced bladder carcinoma: phase II study of the Hellenic co-operative oncology group. Urology. 2004;64:479-84.

10. Bamias A, Moulopoulos LA, Koutras A, Aravantinos G, Fountzilas G, Pectasides $D$, et al. The combination of gemcitabine and carboplatin as first-line treatment in patients with advanced urothelial carcinoma. A phase II study of the Hellenic cooperative oncology group. Cancer. 2006;106:297-303.

11. De Santis M, Bellmunt J, Mead G, Kerst JM, Leahy M, Maroto P, et al. Randomized phase II/III trial assessing gemcitabine/carboplatin and methotrexate/carboplatin/vinblastine in patients with advanced urothelial cancer who are unfit for cisplatin-based chemotherapy: EORTC study 30986. J Clin Oncol. 2012;30:191-9.

12. Maru S, Abe T, Shinohara N, Sazawa A, Maruyama S, Harabayashi T, et al Influence of baseline renal function and dose reduction of nephrotoxic chemotherapeutic agents on the outcome of metastatic urothelial carcinoma: a retrospective study. Int J Urol. 2012;19:110-6.

13. Ichioka D, Miyazaki J, Inoue T, Kageyama S, Sugimoto M, Mitsuzuka K, et al. Impact of renal function of patients with advanced urothelial cancer on eligibility for first-line chemotherapy and treatment outcomes. Jpn J Clin Oncol. 2015;45:867-73.

14. Hussain SA, Stocken DD, Riley P, Palmer DH, Peake DR, Geh Jl, et al. A phase I/II study of gemcitabine and fractionated cisplatin in an outpatient setting using a 21-day schedule in patients with advanced and metastatic bladder cancer. Br J Cancer. 2004;91:844-9.

15. Morales-Barrera R, Bellmunt J, Suárez C, Valverde C, Guix M, Serrano C, et al. Cisplatin and gemcitabine administered every two weeks in patients with locally advanced or metastatic urothelial carcinoma and impaired renal function. Eur J Cancer. 2012;48:1816-21.

16. Kim YR, Lee JL, You D, Jeong IG, Song C, Hong B, et al. Gemcitabine plus split-dose cisplatin could be a promising alternative to gemcitabine plus carboplatin for cisplatin-unfit patients with advanced urothelial carcinoma. Cancer Chemother Pharmacol. 2015;76:141-53.

17. Kaag MG, O'Malley RL, O'Malley P, Godoy G, Chen M, Smaldone MC, et al. Changes in renal function following nephroureterectomy may affect the use of perioperative chemotherapy. Eur Urol. 2010;58:581-7.

18. Lane BR, Smith AK, Larson BT, Gong MC, Campbell SC, Raghavan D, et al. Chronic kidney disease after nephroureterectomy for upper tract urothelial carcinoma and implications for the administration of perioperative chemotherapy. Cancer. 2010;116:2967-73.

19. Rouprêt M, Babjuk M, Böhle A, et al. European association of urology guidelines on urothelial carcinomas of the upper urinary tract 2015, http:// uroweb.org/wp-content/uploads/06-UTUC_druk_LR.pdf

20. Lane BR, Campbell SC, Demirjian S, Fergany AF. Surgically induced chronic kidney disease may be associated with a lower risk of progression and mortality than medical chronic kidney disease. J Urol. 2013;189:1649-55.

21. Cho KS, Joung JY, Seo HK, Cho IC, Chung HS, Chung J, et al. Renal safety and efficacy of cisplatin-based chemotherapy in patients with a solitary kidney after nephroureterectomy for urothelial carcinoma of the upper urinary tract. Cancer Chemother Pharmacol. 2011;67:769-74.

22. Matsuo S, Imai E, Horio M, Yasuda Y, Tomita K, Nitta K, et al. Revised equations for estimated GFR from serum creatinine in Japan. Am J Kidney Dis. 2009;53:982-92.

23. Mizuno T, Ishikawa K, Sato W, Koike T, Kushida M, Miyagawa Y, et al. The risk factors of severe acute kidney injury induced by cisplatin. Oncology. 2013;85:364-9.

24. Moon HH, Seo KW, Yoon KY, Shin YM, Choi KH, Lee SH. Prediction of nephrotoxicity induced by cisplatin combination chemotherapy in gastric cancer patients. World J Gastroentenol. 2011;17:3510-7.

\section{Submit your next manuscript to BioMed Central and we will help you at every step:}

- We accept pre-submission inquiries

- Our selector tool helps you to find the most relevant journal

- We provide round the clock customer support

- Convenient online submission

- Thorough peer review

- Inclusion in PubMed and all major indexing services

- Maximum visibility for your research

Submit your manuscript at www.biomedcentral.com/submit

) Biomed Central 